\title{
Purpura Fulminans in Acute Meningococcemia
}

\author{
Siwadon Pitukweerakul, MD, Pavel Sinyagovskiy, MD, and Pye Phyo Aung, MD
}

Department of Medicine, Presence Saint Francis Hospital, Evanston, IL, USA.

KEY WORDS: Purpura fulminans; Acute meningococcemia; Critical care medicine.

J Gen Intern Med 32(7):848-9

DOI: $10.1007 /$ s11606-017-4017-y

(C) Society of General Internal Medicine 2017

\section{CLINICAL DESCRIPTION}

A 22-year-old woman presented with a 3-day history of fever, vomiting and headache. She denied sore throat, cough, dyspnea or burning urination. On examination, her temperature was $100.5^{\circ} \mathrm{F}$, her blood pressure was $95 / 50 \mathrm{mmHg}$ and her pulse was 112 beats/min. She was acutely ill appearing and lethargic. Examination of her hands and feet are shown in Figures 1 and 2, respectively. Coagulation profiles were consistent with disseminated intravascular coagulopathy. She was treated for septic shock with normal saline, broad-spectrum

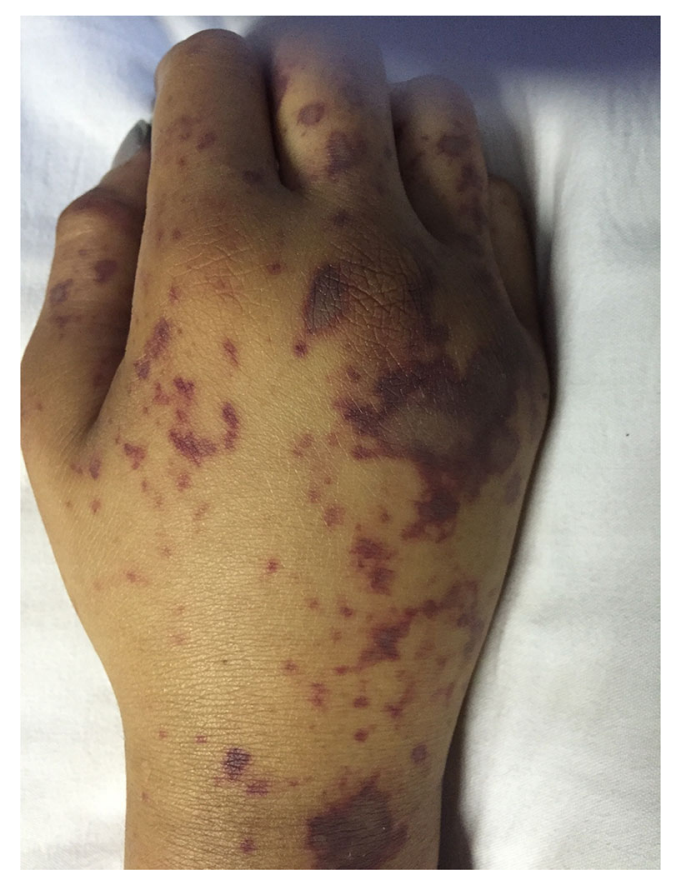

Figure 1 Photograph demonstrating irregular purpuric patches with central necrosis on patient's hand.

Received September 7, 2016

Revised November 10, 2016

Accepted February 10, 2017

Published online February 24, 2017

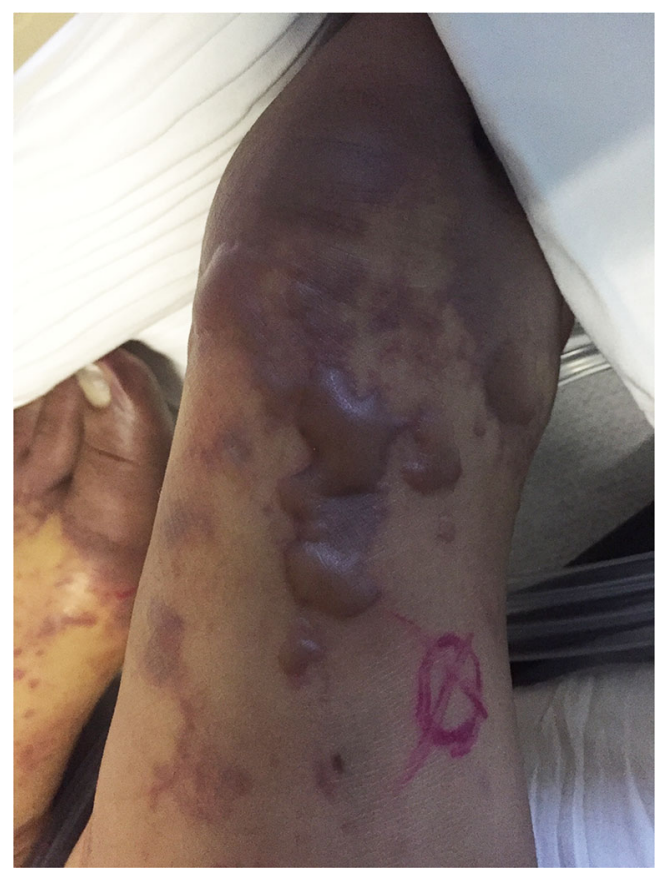

Figure 2 Photograph demonstrating purpuric patches and hemorrhagic bullae on her foot.

antibiotics and protein $\mathrm{C}$ concentrate. She was intubated and required hemodynamic support with vasopressors. Over the next several days she gradually improved. Blood and cerebrospinal fluid (CSF) cultures grew Neisseria meningitidis.

Purpura fulminans (PF) is a severe cutaneous complication of acute meningococcemia. It is characterized by cutaneous hemorrhage and necrosis due to vascular thrombosis of dermis and disseminated intravascular coagulopathy. ${ }^{1} \mathrm{PF}$ is considered an important predictor of poor outcomes following meningococcal infection. ${ }^{1}$ Acquired severe protein $\mathrm{C}$ deficiency in meningococcemia is thought to play an important role in the pathogenesis of $\mathrm{PF}^{2}$ There are no definitive treatments for PF; however, protein $\mathrm{C}$ concentrate, heparin and hemodiafiltration may improve clinical outcome and mortality in patients with acute meningococcemia. ${ }^{2}$

\section{Acknowledgments:}

Contributors: We have no additional contributors other than those listed as Authors. 
Corresponding Author: Pavel Sinyagouskiy, MD; Department of MedicinePresence Saint Francis Hospital, Evanston, IL, USA (e-mail: siwadon.pituk@gmail.com).

\section{Compliance with Ethical Standards:}

Funders: We have no funding sources to declare.

Prior Presentations: This Clinical Image has never been presented at a conference or accepted for publication by another journal or institution.
Conflict of Interest: The authors declare that they do not have a conflict of interest.

\section{REFERENCES}

1. Darmstadt GL. Acute infectious purpura fulminans: pathogenesis and medical management. Pediatr Dermatol. 1998;15(3):169-83.

2. Smith OP, White B, Vaughan D, et al. Use of protein-C concentrate, heparin, and haemodiafiltration in meningococcus-induced purpura fulminans. Lancet. 1997;350(9091):1590-3. 